Methods Clinical and laboratory data of 48 newborn babies in the early neonatal period were studied. 22 babies (main group) had the generalised herpetic infection. The control group was comprised of 26 clinically healthy babies. The intrauterine herpetic infection was diagnosed on the basis of the disease pattern, detected DNA of HSV-1 and HSV-2 in blood and urine, increasing titers of the specific IgG to HSV over time and detected IgM in the blood serum. TLR-2 (CD14 $\left.{ }^{+} \mathrm{CD} 282^{+}\right)$ expression in monocytes was detected by means of cytofluorometry (Beckman Coulter). The polymorphism of allelic variants of TLR-2 genes was studied by means of PCR. The content of IFN-a in the blood serum was determined by immune-enzyme analysis (BCM-Diagnostic, USA).

Results The decreased expression of TLR-2 (CD14 $\left.{ }^{+} \mathrm{CD} 282^{+}\right)$in monocytes of the peripheral blood $(43.8 \pm 8.3 \%$ as against 76.2 $\pm 5.6 \%, \mathrm{p}<0.05)$ was revealed in the main group as compared with the control group. The performed frequency studies of the polymorphism of TLR-2 genes revealed that in the newborn babies with the generalised herpetic infection the frequency of Arg753Gln genotype of TLR-2 gene was significantly higher in comparison with the control group $(26.3 \%$ and $3.8 \%$ correspondingly, $\mathrm{p}<0.05)$. The correlation between Arg/Gln allele of TLR-2 gene and the indices of nonspecific organism protection was revealed. It appeared that the patients, who were carriers of Gln allele in heterozygous condition, the level of IFN-a was significantly different from the indices of the group without the given polymorphism from the statistic point of view $(0.49 \pm$ $0.01 \mathrm{pg} / \mathrm{ml}$ as against $0.1 \pm 0.01 \mathrm{pg} / \mathrm{ml}, \mathrm{p}<0.05$ )

Conclusion The babies with the generalised intrauterine herpetic infection have the decreased expression of TLR-2 in monocytes as well as the allelic polymorphism of TLR-2 gene in the points of Arg753Gln and the decreased level of IFN-a. The revealed peculiarities of the innate immunity factors explain high sensitivity of the newborn babies in relation to the herpetic infection and confirm their role in the development of the disease pattern.

\section{G448(P) NOSOCOMIAL NEONATAL LISTERIA MONOCYTOGENES TRANSMISSION: A REPORT OF TWO CASES AND A REVIEW OF THE LITERATURE}

${ }^{1} \mathrm{~L}$ Fullerton, ${ }^{1} \mathrm{G}$ Norrish, ${ }^{1} \mathrm{C}$ Wedderburn, ${ }^{1} \mathrm{~S}$ Paget, ${ }^{1} \mathrm{C}$ Cane, ${ }^{2} \mathrm{R}$ Basu-Roy. ${ }^{1}$ Paediatrics, Barnet Hospital, Royal Free NHS Trust, London, UK; ${ }^{2}$ Academic Department of Paediatrics, Imperial College London, London, UK

10.1136/archdischild-2015-308599.402

Introduction Listeria monocytogenes is an uncommon but serious cause of neonatal sepsis. There is significant morbidity associated with neonatal listeriosis with reports of $23 \%$ having long term moderate to severe disability at 10 years. ${ }^{1}$ We report the nosocomial transmission of L. monocytogenes IV4 47 from a premature baby with early onset sepsis to a term baby with late onset meningitis. A junior doctor's stethoscope was identified as the likely mode of transmission highlighting the importance of comprehensive infection control precautions.

Methods Clinical governance review led to a root cause analysis and the subsequent need for further evaluation. We searched the literature using terms 'nosocomial infection' and 'Listeria', with filters of 'English language' and 'birth to one month' in order to review the published literature. A poster campaign was initiated following this incident reminding all paediatric doctors attending labour ward, resuscitation and post-natal ward to clean their stethoscopes after contact with each patient.
Results A PubMed search using the search teams 'nosocomial infection' and 'Listeria', with filters of 'English language' and 'birth to one month' returned 28 results. There were 12 case reports of transmission in a shared hospital geographical location however this is the first report of nosocomial transmission of Listeria across different geographical locations within a hospital by an individual's stethoscope. Following the poster campaign there have been no further reports of any nosocomial infection. Conclusion Despite many case reports of nosocomial Listeria transmission in neonates, this still occurs with potential significant morbidity and mortality. Transmission of infection can occur by a variety of ways, which include personnel and equipment. The stethoscope is a vital piece of equipment carried by all doctors. Yet stethoscopes are often not cleaned regularly in between patient contact and are not identified as possible infection sources. Infection transmission is easily preventable by simple measures, which current national guidelines do not highlight. A lack of formal teaching and of senior role models actively cleaning their stethoscopes can contribute to poor stethoscope hygiene, ${ }^{2}$ both of which are easy to address.

\section{REFERENCES}

1 Okike IO, Lamont RF, Trafford Heath P. Do we really need to worry about Listeria in Newborn Infants? PIDJ 2013;32:405-406

2 Saunders C, Hryhorskyj L, Skinner J. Factors influencing stethoscope, Cleanliness among clinical medical students. J Hosp Infect. 2013;84:242-244

\section{G449(P) FACTORS ASSOCIATED WITH EARLY APPLICATION OF OSELTAMIVIR IN CHILDREN WITH INFLUENZA VIRUS INFECTION AND OUTCOME}

R Onita, J Keli, M Eisenhut. Paediatrics, Luton and Dunstable University Hospital NHS Foundation Trust, Luton, UK

\subsection{6/archdischild-2015-308599.403}

Aims Following recommendation by the National Institute for Health and Care Excellence early oseltamivir use is recommended for children at risk because of co-morbidities as there is evidence for reduction of duration of illness. We investigated factors associated with the use of oseltamivir and subsequent respiratory outcome in children with influenza virus infection.

Methods Retrospective study of children attending a District General Hospital with influenza virus infection over a five year period with comparison of groups with and without early application of oseltamivir (within $24 \mathrm{~h}$ of arrival to hospital) regarding age, gender, co-morbidities, type of virus, respiratory support required and duration of stay.

Results We included a total of 70 children, 39 received oseltamivir. Patients receiving oseltamivir had a median age of 35 months (range 7 to 180), patients without oseltamivir treatment had a median age of 16 months (range 7 to 138 ) ( $p=0.004$ ). There was no significant difference in gender, comorbidities (20/39 in patients treated with oseltamivir and $11 / 31$ in patients not treated with oseltamivir), requirement for respiratory support (13/39 in patients with and 6/31 in patients not receiving oseltamivir) or duration of stay in hospital between groups. Two patients receiving oseltamivir but none in the group without oseltamivir treatment required mechanical ventilation. Patients without oseltamivir treatment were significantly more likely to be infected with influenza B virus.

Conclusions Patients treated with oseltamivir were significantly older and less likely to have influenza B virus infection in our study population. 